\title{
Preparing UK tennis academy players for the junior-to-senior transition: Development, implementation, and evaluation of an intervention program
}

Elizabeth K.L. Pummell

David Lavallee

This is the accepted manuscript (C) 2015, Elsevier Licensed under the Creative Commons AttributionNonCommercial-NoDerivatives 4.0 International (CC BY-NC-ND 4.0) http://creativecommons.org/licenses/by-nc-nd/4.0/ (oc) Er-Ne-No

The published article is available from doi: http://dx.doi.org/10.1016/j.psychsport.2018.07.007 
1 Preparing UK tennis academy players for the junior-to-senior transition: Development,

2 implementation, and evaluation of an intervention program

3

4

5

6

7

8

9

10

11

12

13

14

15

16

17

18

19

20

21

22

23

24

25 
Abstract

\section{Objectives}

3 The current case study aimed to develop and evaluate an intervention program to aid

4 preparation for the junior-to-senior transition (JST) in sport, which provides a novel

5 contribution to the existing professional practice literature. The program, based upon existing

6 theory, focused on developing resources, knowledge and readiness to cope with the

7 transition. The authors were particularly interested in exploring the participants' evaluations.

\section{Design/Method}

9 A symbolic modeling approach was adopted, in which 5 senior tennis players were recorded

10 on video discussing the demands of and coping strategies for the JST. The videos were used

11 to support the intervention and delivered over 11 weeks to 7 junior tennis players from an

12 elite training program in the U.K. $(M=15.1$ years, $S D=1.24)$. To evaluate the

13 intervention, a mixed methods single-subject design was used, with readiness to cope,

14 knowledge and athletic identity assessed at three time points, along with social validation.

\section{Results}

16 Social-validation data indicated that the participants placed value on the intervention as a

17 means to prepare for transition, citing increases in knowledge, coping, confidence and

18 transition related skills. Quantitative data demonstrated an increase in readiness to cope with,

19 and an increase knowledge of the JST. Athletic identity showed a small decrease.

\section{Conclusions}

21 The current study supports existing research upon the value of preparation for transition in 22 sport, with this the first transition preparation program for the JST well received by athletes.

23 Further research is required to explore longitudinally how such interventions contribute to a successful JST.

25 Keywords: within career-transition; athlete development; tennis; applied case intervention. 
Preparing UK tennis academy players for the junior-to-senior transition: Development, implementation, and evaluation of an intervention program

Practitioners engaged in the development of young elite athletes strive to maximize the rate of successful transition from junior to senior level, however, the dropout rate at this stage of athletic development is high. Research in Belgium has demonstrated that $24 \%$ of elite junior athletes failed to continue to senior level and that only $17 \%$ made a senior national team (Vanden Auweele, De Martelaer, Rzewnicki, De Knop, \& Wylleman, 2004). Unsurprisingly therefore, the junior to senior transition (JST) is considered the most difficult of within-career athletic transitions (Stambulova, 2009) and consequently, preparation of the athlete is worthy of continuing research attention.

According to Schlossberg, transitions involve 'a change in assumptions about oneself and the world and require a corresponding change in one's behavior and relationships' (Schlossberg, 1981, p. 5). The individual's perception of the transition, the availability of support and their coping skills are all critical factors in the ability to adapt. However, whilst research into the JST reveals the need for significant adjustment, athletes often have limited knowledge of the associated demands, are likely to over-estimate their readiness to cope (Stambulova, Pehrson \& Olsson, 2017) and on discovering that they do not have the necessary resources, they may drop out or find themselves in crisis (Stambulova, 2000; 2017).

For some time, the importance of acquiring such relevant knowledge, the development of coping skills and goal setting to navigate the associated demands, have been acknowledged and demonstrated to be of value at transition (Danish, Petitpas \& Hale, 1995), with extensive research at the retirement transition (e.g. Grove, Lavallee, Gordon \& Harvey, 1998; Pearson \& Petitpas, 1990). Now, more recent research has offered additional support regarding within-career transitions. In Morris, Tod and Oliver's (2015) analysis of the 
1 organizational structure of transition support for the JST in British football clubs, junior

2 athletes benefitted from insight concerning the demands of professional football, with this

3 ideally being delivered by staff with relevant specialist knowledge, such as sport scientists. A

4 realistic picture of the significant challenge ahead was welcomed by players. Sources of

5 support were also identified as vital, thereby echoing Stambulova's (2003) emphasis upon

6 achieving a proper balance between demands and resources. Research in tennis endorses this

7 perspective, with the appropriate organizational support being fundamental to successful

8 progression to the top of the rankings (Matthews, Farrow, MacMahon \& Weissensteiner,

$92012)$.

Exposure to senior/elite sport and to role models in the form of senior peers can also

11 contribute towards a successful transition (Bruner, Munroe-Chandler \& Spink, 2008). This not only instils readiness to cope with transition (Bruner et al., 2008), but alongside education enhances athletes' comprehension of the transition process, of the expected physical and mental demands, and of the personal characteristics required. These are factors demonstrated to encourage successful adaptation (Morris et al., 2016). Furthermore, Stambulova and colleagues recently examined the phases of transition in Swedish ice hockey players, finding that role models were especially important in the early stages of transition, when young athletes look to their senior peers for encouragement and to help understand what to do and how to behave at senior level (Stambulova et al., 2017). This kind of informational support from more senior athletes is a valuable resource, allowing young athletes to gain knowledge

21 of norms of the senior environment, including the performance and lifestyle demands

22 inherent in participation at senior level, together with the opportunity to model the behavior of more experienced peers (Pummell, Harwood \& Lavallee, 2008; Pehrson, Stambulova \&

24 Olsson, 2017). Even at retirement, Grove et al. (1998) identified that the sharing of transition 
1 experiences by senior role models can not only prove therapeutic, but also prompts current

2 athletes to begin to prepare for their own transition.

The athletic career transition model (Stambulova, 2003) proposes that successful

4 transition is determined by the navigation of specific transition demands (e.g., a higher

5 playing level), for which the athlete needs coping resources such as knowledge, skills,

6 motivation, social, informational and financial support. The demands to which athletes are

7 exposed are also affected qualitatively, by interactions between athletic, psychological,

8 psychosocial, academic/vocational and financial levels of development. According to the

9 holistic athletic career model (Wylleman, Reints, \& De Knop, 2013), those supporting an

10 athlete's development should take a whole-person approach, being mindful of the progression

11 at these different levels, with concurrent transitions probable. Indeed, the model anticipates

12 that the JST is likely to coincide with a transition into higher education or to becoming a

13 (semi-) professional athlete, with an associated broadening of one's social network and with

14 the need to become more financially independent and/or to seek support from sponsors or the

15 governing body. Thus, there are several transitional challenges in a relatively short time,

16 making this period of an athlete's life a particularly exacting one and subsequently requiring

17 more support. However, whilst the existing literature endorses the value of preparation to

18 bolster resources and to overcome barriers (e.g. Morris, Tod \& Oliver, 2016), interventions

19 designed to provide such preparation are scarce.

In response, the authors of this current study aim to develop, implement and evaluate

21 an intervention to prepare athletes in an international high-performance tennis center in the

22 United Kingdom for the JST. Whilst junior success can be an indicator of later professional success in tennis, the majority of variance in professional rankings remains unexplained

24 (Bane, Elliott \& Reid, 2016). The professional tennis circuit is a particularly challenging environment for aspiring players, lasting 11 months of the year and taking elite junior players 
1 from the relative comfort of the top level junior tournaments, to low level senior tournaments

2 with limited prize money, difficult playing conditions and often reduced support due to a lack

3 of funding, lack of availability of appropriate role models, and extensive travel (Pummell \&

4 Lavallee, 2009). This background creates an appropriate context for intervention, offering

5 coaches, sport scientists and organizations the opportunity to support junior athletes in their

6 preparation for, and in the navigation of the transition.

7

8

The specific aims of the current study are therefore to: i) develop an intervention program to aid preparation for the JST, based upon existing literature, which provides a novel contribution to the professional practice literature; and ii) to implement the program, evaluate the effects, and evaluate the program itself. There are calls for sporting organizations to establish better links between their junior and senior departments, including through the creation of opportunities for role models to assist with preparation for transition (Stambulova et al., 2017), and the methodology of this study, which draws upon senior role models, is consistent with that goal.

The design of the current study is comprised in two phases, with the first constituting the development of the intervention, and the program which resulted and the second covering the implementation and participants' evaluations. The intervention took place at a nonresidential high-performance tennis center in the United Kingdom, with players registered on the elite training program. These athletes benefitted from access to highly trained coaches, as well as specialized sport science support, and received their education as part of the academy set up.

\section{Phase 1: Development of the Intervention Program}

\section{Phase 1 Method}

Research-Informed Intervention. The intervention content was designed to help the participants understand the demands associated with the JST and to build the resources 
1 required for successful transition. The structure and content were inspired by established

2 frameworks emphasizing the importance of a balance between demands and resources in

3 order to sustain optimal adjustment (Schlossberg, 1981; (Stambulova, 2003; Wylleman et al.,

4 2013). Interviews with athletes and with stakeholders have demonstrated that knowledge of

5 the transition process and realistic expectations about life as a senior athlete are important for

6 readiness for the transition (Bruner et al., 2008; Morris et al., 2016), and therefore the authors

7 aimed to develop an intervention program which supported athletes' adjustment by providing

8 them with such informational support. More specifically, a 'whole-person' focus to the

9 content was sought, derived from the five levels of the holistic athletic career model

10 (Wylleman et al., 2013), and related research (e.g., Rosier, Wylleman, De Bosscher \& Van

11 Hoecke, 2015). At the athletic level, the program emphasized the higher performance

12 standards expected and the difference in both the nature and intensity of lifestyle demands of

13 senior level tennis. These factors encompass, for example, what to expect from the senior

14 tour at the psychological level, the increased responsibility, independence and discipline

15 required (Pummell \& Lavallee, 2009; Rosier et al., 2015; Stambulova et al., 2017), as well as

16 developmental responsibilities critical to the status of a successful senior athlete, such as a

17 healthy diet (Stambulova, Alfermann, Statler \& Côté, 2009). Psychosocially, the participants

18 were educated about changes in their support structures and where to seek support (Pummell

19 \& Lavallee, 2009; Rosier et al., 2015; Morris et al., 2016). Academic development was

20 discussed, alongside skills such as time management (Stambulova et al., 2009), and the

21 financial demands of the transition were explored, together with strategies for managing

22 greater financial independence and seeking financial support (Stambulova, 2003).

When considering the optimal sources of informational support for the JST, research

24 has demonstrated the importance, not only of specialist sport scientists, but also of role 
1 interact with senior players (e.g. Morris et al., 2015; Stambulova et al., 2017). However,

2 given the demanding travelling schedules of elite senior tennis players, they are only

3 infrequently available to interact with aspiring juniors. In addition, at lower level senior

4 tournaments, where juniors often get their first taste of senior competition, there is a potential

5 for inappropriate role models to be identified; those who do not demonstrate the types of

6 professional behaviors and attitudes conducive to progress, and who are themselves unlikely

7 to progress (Pummell \& Lavallee, 2009). It is therefore important, not only that there are

8 opportunities for role modeling, but that the role models available are appropriate. The

9 solution adopted in the current investigation, was to provide informational support from role

10 models via video. According to social cognitive theory (Bandura, 1989), symbolic (video)

11 modeling can significantly impact learning. It is also a means through which an individual,

12 highly relevant model can provide opportunities for learning to a greater number of

13 participants than would otherwise be possible.

Role models. The role models, in this intervention, were five current senior tennis

players who were contacted via the first author's contacts with the national association. A

semi-structured interview guide was developed, based upon the demands of transition

identified in theory and research (e.g, Schlossberg, 1981; Stambulova, 2003, Wylleman et al.,

2013), with each role model being interviewed, and video-recorded, with consent to discuss

their experiences on the tour and their own JST. The role models were chosen to be credible

and relevant due to their similar characteristics (both male and female role models) and prospective participants. They had made the transition to senior level at least one year prior, with the most experienced player having transitioned to senior level 14 years prior. Role models had rankings ranging from 500 up to the top 100 in either singles or doubles. Of those 
1 reflecting the typical pathway in professional doubles tennis. Across the role models, there

2 was therefore considerable experience and knowledge of the senior tennis tour.

3 Phase 1 Results

4

The video interviews were edited into clips and organized into 10 topics relevant to the transition in tennis, detailed in Table 1. Titles and a narrative were added to the videos in order to add context to the content, and discussions and activities supplemented the video content and encouraged the participants to apply content to their own transition. For example, week 1 comprised an introduction to the JST, with senior role models discussing their experiences of making the step up from junior to senior tournaments. Supporting information from men's and women's tennis was used to educate participants about the types of tournaments at senior level, and how ranking points are collected. In week 2, videos with senior role models included the differences between playing tennis at junior versus senior level both on-court and off-court, including fitness and performance demands, as well as the lifestyle of a senior player. The participants subsequently identified differences between the performance and lifestyle demands as an elite junior, and those of a senior player, and set realistic goals to begin to address some of these differences. Weeks 3, 4 and 5 focused on psychological demands, mental skills and professional behaviors at senior level. Profiles of current top players were used as examples to illustrate the typical (non-linear) progress of a tennis player, and participants identified areas in which they could take on greater personal responsibility and demonstrate more professional behaviors (such as match preparation) ahead of transition. The second half of the program included a focus on scheduling of tournaments and discussion of the additional demands imposed by this over and above the participants' current tournament schedule (week 6). There was identification of opportunities for support (week 8) and how to maximise the support and knowledge currently available at the academy. Players were also asked to review and update their goals in week 7 and again in 
1 week 10 following information from senior role models about preparation for the JST and

2 phases of the transition in tennis.

Phase 2: Implementation and Evaluation of the Intervention Program

\section{Phase 2 Method}

5 A single-subject mixed methods design was employed, with data collected at baseline, at the

6 mid-point of the intervention and at its conclusion. Given the exploratory nature of the

7 research, the participants' evaluation of the intervention at its termination was collected

8 through social validation.

Participants. Following institutional ethical approval, a letter, along with a consent

form was sent to all 12 players (and their parents), aged between 13 and 16 years, who were registered on the elite training program at a high-performance tennis center in the United

Kingdom. This age group is considered appropriate given calls to support the development of appropriate knowledge, skills, motivation, and coping mechanisms for transition once young athletes enter a professional environment (Morris et al., 2016). Whilst the younger players on the elite training program had a number of years still remaining in junior tennis, ethically it was judged appropriate, to maximize benefit by offering the intervention to all (British Psychological Society, 2014). Potential participants were offered a place on a sport psychology program on the topic of the junior-senior transition. Of the twelve players contacted, eight returned their consent forms, and seven players (three females, four males) completed the program $(M=15.1$ years, $S D=1.24)$. All the tennis players who took part were competing at national and/or international junior tournaments. The national rankings of the seven participants were obtained at the beginning of study; with three ranked within the top 20 players of their age group, and a further two in the top 50. The remaining two participants were ranked between 70-80 and 110-120. 
Intervention. The intervention program, took place in weekly 1.5 -hour sessions over

211 weeks, to fit in with the schedule of the tennis academy, which followed the academic

3 calendar in the U.K. Weeks one to 10 consisted of delivery of the intervention content, as

4 detailed in Phase 1. Data were collected at three time points (week 1, week 6 and week 10), with week 11 consisting of social validation. Repeated measures were taken under the same conditions, i.e., with the location, time of day, and instructions given standardized for each data collection point.

Steps were taken to maximize learning through the symbolic modeling intervention, in accordance with Rosenthal and Bandura (1978) and not to overload the participants. The videos were therefore of no more than 20 minutes duration before a break for discussion with and between the participants. At the end of each session a 'reflection sheet' was presented to each participant, requiring them to identify the three elements from each session judged to be of most personal significance, in the context of their own JST (Rosenthal \& Bandura, 1978). This also provided a means for the researcher to check comprehension of the material, in order that omissions or misconceptions could be corrected by additional discussion or explanation (Bandura, 1989).

To enhance the participants' preparation for transition further and to consolidate their learning, a diary for recording personal reflections between every session was developed. This was designed to encourage them to revisit and to apply the knowledge and strategies which the role models had shared. Time was scheduled at the beginning of each session to discuss reflections from the previous week. Research suggests this is important for young athletes preparing for the JST (Morris et al., 2016) and participants were encouraged to share the thoughts and feelings which emerged as a consequence with senior players (who whilst not permanent fixtures at the academy, sometimes visited for short training blocks) and with former senior players (now coaches) in the academy. The final element of behavioral 
1 reinforcement (important in sustaining the enactment of learned behaviors; Bandura, 1989)

2 was the involvement of the academy coaches, who were recruited to support the

3 intervention's aims. Provided with a written overview of the week's intervention topic, the

4 coaches were asked to acknowledge and positively to reinforce the display of transition

5 appropriate behaviors which had been covered in the program. This strategy was adopted to

6 build the participants' efficacy in their ability to perform the transition-related behavior

7 which they had learnt to be important, and to provide additional social support in this process.

8 With social support considered the most critical external resource at the JST (Stambulova,

$9 \quad$ Franck \& Weibull, 2012), and verbal persuasion and successful performance of skills being

10 two predictors of self-efficacy beliefs (Bandura, 1989), this was an important element of the

11 intervention. To motivate the coaches to reinforce behaviors, they were asked to record the

12 number of relevant interactions with the participants.

13 Assessment. On the basis of the research reviewed previously, the authors

14 hypothesized that the symbolic modeling intervention described here would improve

15 knowledge of the JST transition demands and readiness to cope with the transition amongst a

16 group of junior tennis players. Given Schlossberg's (1981) definition of transition, which

17 suggests that there is a change in how the individual views him/herself at transition, and

18 research in sport has supported this, highlighting significant identity development through

19 career transition (e.g., Brewer, Van Raalte, \& Linder, 1993; Stambulova, 2009), we were also

20 interested to examine the effect of the intervention on athletic identity. In fact, a high level of

21 athletic identity has been shown to be facilitative of within-career transition (e.g.

22 Poczwardowski, Diehl, O’Neil, Cote, \& Haberl, 2013; Franck, Stambulova \& Weibull,

23 2016), because it usually manifests as a strong commitment to the sport which is beneficial

24 when attempting to break into the senior ranks. However, in view of research indicating that

25 athletic identity is already high amongst adolescent elite athletes and remains high (Houle et 
1 al., 2010), we predicted that the participants would already demonstrate high athletic identity

2 and that the intervention would not significantly increase this.

3

4

Measurement of the dependent variables was via questionnaire and perceptions of the program were assessed via social-validation. Athletic identity was assessed using the Athletic Identity Measurement Scale (AIMS; Brewer et al., 1993; Brewer \& Cornelius, 2001), and readiness to cope with transition by a modified version of the Transition Coping Questionnaire (TCQ; Schlossberg, 1993). Knowledge of transition demands was assessed via a self-report measure designed for this study.

Athletic identity. The seven-item AIMS (Brewer \& Cornelius, 2001), assesses the strength and exclusivity of identification with the athletic role. Participants respond to the items on a scale from 1 (strongly disagree) to 7 (strongly agree). In the present study, internal consistency of the scale was $\alpha=.73$ (pre-intervention), $\alpha=.67$ (at mid-point assessment), and $\alpha=.77$ (post intervention), suggesting adequate reliability.

Readiness to cope with the transition. A modified version of the TCQ (Schlossberg, 1993) was used to assess perceptions of readiness to cope with the future transition. The original TCQ contains 45 questions that ask respondents to rate themselves in four areas: i) their Situation (i.e., how they see the transition that they are facing), ii) the Self (i.e., personal characteristics that they bring to the transition), iii) the Supports they have (i.e., what help they have from others), and iv) their coping Strategies (i.e., the skills they possess to cope with the transition). This questionnaire has previously been used with sport populations in relation to career termination (Lavallee, 2005) and research has demonstrated strong validity and reliability (Schlossberg, Waters \& Goodman, 1995). However, some of the items in the original questionnaire were deemed inappropriate for the specific transition under investigation and for junior athletes, being focused on life transitions for adults. These were either removed or the wording modified for the specific transition context, i.e. the JST. The 
1 four areas of the TCQ were retained, and each participant's perception of their coping ability

2 was assessed using 22 items on a seven-point Likert-type scale from 1 (not at all true) to 7

3 (completely true). Items included: 'If I was to make the transition to senior level right now, it

4 would cause stress in my life' (Situation), 'Right now, I have a clear idea about how to make

5 it to senior level' (Self), 'Right now, I receive support from my coach for the transition to

6 senior level' (Supports), and 'Right now, I have specific goals which I've set to prepare

7 myself for the transition from junior-to-senior level' (Strategies). The Cronbach's alpha

8 coefficients for this study across the four subscales and three time-points were acceptably in

9 the range $\alpha=.67$ to $\alpha=.92$, with the exception of the Situation subscale when administered pre-

10 intervention, which yielded a co-efficient of $\alpha=.40$. The relevant results should therefore be

11 interpreted with caution.

12 Knowledge. In order to assess knowledge, given the lack of an existing tool, a pool of items relevant to the junior-senior transition was developed based on theory and the demands of the JST identified in the literature (including Pummell \& Lavallee, 2009; Stambulova, 2003, 2009). Items were checked for face validity by two experts in the area of within-career transition, and the measure was pre-tested with four junior tennis players. Participants rated their current knowledge using a visual-analogue scale, as well as identifying a knowledge goal to empower and motivate them to direct their preparation (Danish et al., 1995). Participant responses were determined by measuring from the left-hand side of the scale to the marked response, with anchors of 'No knowledge', 'Some knowledge', and 'Great

21 knowledge', and a maximum scale score of 150. Questions asked participants to give their perspective on their current level of knowledge about various aspects of the transition, including the differences between the tennis played at junior and senior level, what senior players have done on and off the court to prepare themselves to make the JST, and the type and amount of training required at senior level. 
The final stage of the intervention in week 11 involved a qualitative examination of

2 the participants' perceptions of the program. Social-validation is often used after the

3 conclusion of an intervention to assess: the extent to which the target skill is important to the

4 target population, if the procedures are effective and acceptable, and if the participants are

satisfied with the results (Hrycaiko \& Martin, 1996). As such, participants were posed a

series of questions which asked them to reflect on the program, alongside survey style

questions to rate the intervention's impact upon their preparation, readiness to cope, and

knowledge of the JST (on a seven-point Likert-type scale from 'not at all' to 'very much so').

9 These questions included: 'To what extent do you feel more confident in your ability to make

10 the transition from junior to senior level than you did before the program?', 'To what extent

11 do you feel that you have developed skills which will be useful to you for making the

transition?'. Based on the responses given, participants were then asked to elaborate on their response in a qualitative manner with follow-up questions such as 'In what ways do you feel more confident for the transition?', or 'What skills have you developed?' These follow up questions were designed to elicit greater depth, giving insight into the idiosyncrasies of that participant's experiences.

Data analysis. Data were inputted into Microsoft Excel, and graphically illustrated to visually examine the effect of the intervention on the dependent variables. This is a process deemed acceptable in single case design where the examination of practical significance is appropriate. Hrycaiko and Martin (1996) state that the following principles can be used to guide the visual analysis: i) baseline assessments are stable or in the opposite direction to that expected due to the intervention; ii) any effect during intervention is replicated both within and across participants; iii) few overlapping data points exist between the baseline and intervention assessments; iv) that an effect occurs soon after introduction of the intervention; 
1 (Hrycaiko \& Martin, 1996). Conditions ii-vi are relevant to the design of the current study.

2 Hrycaiko and Martin also propose that to assess the practical significance, one must examine

3 the social validity of the change, and therefore responses to the qualitative social-validation

4 questions were transcribed and are reported verbatim alongside the relevant quantitative

5 results. Deductive content analysis was used to organize the quotes into themes according to

6 the topics of the quantitative social validation questions. Quantitative data from the social

7 validation questions was analyzed descriptively in order to report mean values for each

8 question.

\section{$9 \quad$ Phase 2 Results}

10 Seven junior tennis players completed the intervention program, with one male player

11 dropping out due to competing time demands. Descriptive statistics are presented in Table 2.

12 Verbatim quotes from the interviews are presented in the text, with relevant comments highlighting the participant's perceptions relating to knowledge, readiness to cope, and athletic identity, and their ratings of change in these domains. Following this, quotes relating to the participants' general perceptions of and reflections on the program are included.

Knowledge. The data in Table 2 indicate that the participants demonstrated an increase in transition-related knowledge during the intervention. There was a greater increase for all participants in knowledge from Time 1 to Time 2 than Time 2 to Time 3 . All participants demonstrated this profile, with the exception of participant 4 , who had the greatest increase from Time 2 to Time 3.

With the exception of participant 3, who rated their increase in knowledge as a result of taking part in the program at 4 (on a scale of 1-7), all participants rated this at 6 or 7 during the social-validation phase $(M=6.28 ; S D=1.11)$. Participant 5 confirmed the discrepancy between their transition-related knowledge pre- and post-intervention: 
I really didn't have a clue what the senior tour was like at all before I did the program. I didn't know like any of the tournaments, any of the lifestyle. I didn't know anything. And now I'm informed and I know how to do it and how people have done it....At the start because I didn't know much about senior tour, I was just thinking 'oh, I know I know everything I need to know, this is going to be a waste of time', and then when we went in there and we watched the videos and we watched the players talking, it was like there's so much more to it and you don't even realize it.

Coaches also related aspects of training sessions to the senior level and encouraged participants to think about their preparation:

It's again, like enforcing the fact that senior players and [the] senior tours are a lot different from the juniors and that we have to be ready for it - and that if we're going to make it we have to do certain things to make it (P4).

Readiness to Cope with the Transition. As shown in Table 2, the overall readiness of the group increased from Time 1 to Time 3, with a mean increase of $13.43(S D=15.51)$, and there was an increase from pre- to post-intervention on all four of the TCQ subscales. The mean increase for the Situation subscale was $5.0(S D=5.30)$, for Self, the mean increase was $3.71(S D=3.40)$, for Supports the mean increase was $0.43(S D=2.57)$ and for Strategies, $4.29(S D=8.10)$. The group showed a mean increase from Time 1 to Time 2 and Time 2 to Time 3 on all of the subscales with the exception of Supports which showed a mean decrease from Time 1 to Time $2(M=-1.71, S D=2.06)$, before then increasing above the initial level at Time 1.

In the social-validation phase, participants felt that taking part in the intervention had left them more prepared to cope with the transition, with a mean rating of $6.14(S D=0.69)$. Each participant rated the improvement in their feelings of coping at six or seven on the seven-point Likert-type scale. Participant 4 commented: 
I feel like more, more prepared as in I just know more about things, like the tournaments and the, like the scheduling plans and things like that. I just feel like I know like how to get myself ready [for the transition].

During the program, participants perceived that they had developed skills which would help them to cope with the JST (with a mean rating of 5.43, SD $=0.79$ ). These skills were varied and included: organization skills, tournament planning and scheduling, the ability to deal with setbacks, match preparation, and independence:

I'm a bit more like independent in choosing the stuff I want to do. Because like if you're going to be a senior player you can't really rely on, too much on, loads of other people. So I'm taking things like into my own account, and doing, trying to do more stuff on my own, instead of asking people to do it (P2).

However, participant 6 thought that the skills learned would be useful later: "I think as I get older then I think it will have more of an effect because it will, you will have to realize the realities of it, I'll use those things, definitely".

The social-validation data also suggested that efficacy in one's ability to make the transition was increased by participation in the program (with a mean rating of $5.71 ; S D=$ 0.95). Participant 4 suggested that confidence for the transition came from realizing how to deal with setbacks, and this also fostered a commitment to keep trying: It just like makes you think that you can deal with things rather than 'what would I do then?' And makes you feel more confident if that happened. So, like you'd be more committed to do it because you wouldn't be so scared of things like that happening. I feel more confident now like about what's going to happen.

The development of specific skills and confidence in one's ability to cope with the demands associated with senior tennis were also important: "I know that I could plan my tournaments 
1 by myself, I know that I'll be able to also like sort out where I'll be staying and everything"

2 (participant 7).

3

Athletic Identity. Athletic identity showed little change for any of the participants (the group as a whole showed a marginal decrease of $0.14(S D=3.24)$ from Time 1 to Time 3. Only one participant (participant 4) showed more than a two-point change on the scale from pre- to post-intervention. Despite these results suggesting little change in commitment to the athlete role (i.e., athletic identity), during the social validation stage, all participants reported increases in commitment to making the transition to senior level and therefore pursuing life as a professional tennis player $(M=5.07, S D=1.17)$. Participant 5 , who rated their increase in commitment to the transition at 6 on the 7-point scale, commented that: Because of the information we were finding out, and as the tour seemed to get more and more complicated we were paying more and more attention so, and when we found out how hard it is we were more committed. We were thinking 'God, if we don't get, if we don't buck up our ideas we're not going to do very well are we?' So now we're more committed to doing the correct things.

Participants' General Perceptions of the Program. As a group, the participants rated the information included in the intervention as very useful $(M=6.29, S D=0.76)$. The participants especially appreciated the opportunity to hear first hand experiences from senior players, for example, participant 3 commented:

It wasn't just like saying, 'oh well, this person did that', it's rather they're actually telling you that they did it, so it's like you getting it first-hand....They were talking like in real life, so you saw the people saying it themselves, so you're probably more inclined to believe it because they're saying it.

Opinions on the most valuable part of the intervention varied between participants, but knowledge of, and a heightened commitment to the transition demands was apparent, 
1 with participant 5 reporting a greater understanding of the need to prepare for the transition,

2 rather than waiting for it to happen:

3

4

Before going to this program I was quite naïve about the transition. I was thinking, 'yeah, it's three years away, who cares, you know, when actually I need to be starting to prepare for the transition now, like in my responsibility, my commitment, my preparation; all these things.

\section{Discussion}

The current study aimed to provide a novel approach to the preparation of athletes for the JST. Specifically, the aims were to: i) develop an intervention program to aid preparation for the JST, based upon existing literature, which provides a novel contribution to the professional practice literature; and ii) to implement the program, evaluate the effects, and evaluate the program itself. Previous research has demonstrated the key role of preparation for this transition (e.g., Morris et al., 2016), but none has so far implemented intervention based on this understanding. The current study therefore represents a valuable first contribution to an area in which intervention has so far been neglected. The results suggest that using role models via symbolic modeling to provide informational support can provide junior athletes with knowledge of senior sport and is perceived as valuable preparation by junior tennis players.

Danish and colleagues (1995) propose that intervention should aim to prepare athletes for an upcoming transition through the teaching of relevant skills, the imparting of appropriate knowledge and establishment of self-efficacy for the transition. In terms of the JST, this empowerment process requires a comprehensive familiarization of the athletes with the senior tennis tour, based around a plan for transition, and including goal setting targeted on relevant behaviors and skills. The current study reflected these goals and the quantitative and social-validation data imply that the participants indeed felt more confident, prepared for 
1 and knowledgeable about the transition as a consequence. Beyond the specific dependent

2 variables, there was also a perception by the participants that it had been useful to them, and

3 that they had developed skills which they could utilize in the future, with high ratings for

4 perceived increase in knowledge and coping.

Commitment to making the transition was the factor upon which participants rated

6 themselves lowest post-intervention, although they still reported an increase. This lower

7 rating was perhaps affected by the realization that the transition would be more difficult than

8 some of the participants had initially expected. Upon making this discovery during the

9 program, it is possible that the participants concerned may have begun to (re)consider their

10 chosen career path. However, given that many athletes prematurely commit to a career in

11 their sport without considering other options (Brewer, Van Raalte \& Petitpas, 2000), a

12 program such as this, which seeks to reflect the reality of life as a senior athlete, might help to

13 prevent or reduce the likelihood of such a foreclosed identity. Given the evidence (e.g.,

14 Brewer, 1993, Mussweiler, Gabriel, \& Bodenhausen, 2000) that a foreclosed identity may be

15 negative for adjustment to setbacks and the inevitable social comparison in sport, this is an

16 important consideration, worthy of further research. The qualitative results in relation to

17 commitment were reflected in the quantitative results, with minimal change in athletic

18 identity. Although an increased identification with the role of athlete would be anticipated at

19 the JST (on the basis of existing literature, e.g., Brewer et al., 2000), the participants in the

20 current intervention program were not actually undergoing the transition at the time of the

21 intervention, but were merely preparing for it. If the program prompted the athletes to re-

22 evaluate their commitment to a career in the sport, it was perhaps too early in the transition

23 process to discern any significant shift in athletic identity related to the forthcoming move to

24 senior level. Indeed, theory and research suggest that a modification in the identity hierarchy,

25 i.e., an identity becoming more or less salient, is likely to occur when there is an alteration in 
1 the circumstances which relate to that identity, such as a modification in relevant

2 relationships and behavior (Cassidy \& Trew, 2004; Schlossberg, 1981). However, during a

3 preparatory transition program, relationships are likely to have remained stable (given the

4 lack of real-life contact with senior athletes), and the athletes were not yet required to (and

5 were only just learning of the need to) adapt their behavior. Whilst the effect on athletic

6 identity of a transition preparation program has not previously been explored, it may

7 therefore have been premature to expect any change in the salience of athletic identity at this

8 stage.

Whilst the social validation data are considered key in this study, the quantitative data are also worthy of further discussion, although when interpreting this data, readers should be mindful of limitations in the current research. The results have been derived from a small sample, with a single-case design, in which multiple-baseline assessments were not possible due to the time constraints of the tennis academy adhering to the academic term in the United Kingdom and to players' travelling schedules either side of this. Nevertheless, there were consistent patterns across the group, with all participants reporting an increase in knowledge of transition demands. The data adhered to the relevant principles set out by Hrycaiko and Martin (1996) for visual inspection, i.e. that the increase was seen both within and across participants, there were no overlapping data points, a large effect is seen at the beginning of the intervention, and the results were as expected in relation to previous research highlighting a need for informational support at the transition (Stambulova, 2003). The effect of the

21 intervention on readiness to cope with the transition reveals an increase throughout the intervention for four of the participants, with three demonstrating a small decrease, either from time 1 to 2 , before increasing to time 3, or from pre to post intervention. Athletic identity demonstrated little change for six of the participants. The largest change is evident in participant 4, who was also the only participant to show no increase in readiness to cope with 
1 the transition at time point 2 or 3 . Although a large change was not expected for athletic

2 identity, as already discussed, the results for readiness to cope with the transition warrant

3 further examination, particularly with a larger sample.

Whilst the change in readiness to cope with the transition was less consistent than the increase in knowledge, across the participants there was good evidence for an increase in

6 perceived coping readiness having occurred over the duration of the program, based on the

7 results from the modified TCQ (Schlossberg, 1993), with increases on all of the four

8 subscales (Situation, Self, Supports and Strategies). However, as reported, scores on the

9 Supports subscale decreased from pre- to mid-intervention, before returning to and then

10 exceeding the pre-intervention score at conclusion of the program. It is unclear why this

11 pattern of results emerged. Questions in this subscale relate to support from peers and

12 particularly from coaches, for the transition. It is possible that whilst they were receiving

13 information about the senior tour from their coaches, the participants discerned an accusatory

14 tone. Coaches were asked only to reinforce the messages from the current week's

15 intervention session, but the participants reported that coaches pointed out the differences

16 between the behavior or skills which they, as junior players, had demonstrated, and those of

17 the players on the senior tour (i.e., this is how you are, and this is how you should be).

18 According to discrepancy theory (Higgins, 1987), the expectations one perceives significant

19 others have of the self can result in psychologically distressing emotions when it is apparent

20 that this 'ought' self is not met. Consequently, the participants may have perceived the

21 coaches to be critical rather than autonomy-supportive (Mageau \& Vallerand, 2003).

22 Alternatively, it may be that, with the increase in knowledge of the demands of the transition

23 (which was most marked from Time 1 to Time 2, when there was a concurrent decrease on

24 the Supports subscale), the participants felt overwhelmed by the complexities of what they

25 might face and perceived that there was not enough support available to help them to make 
1 the transition successfully. Although this aspect requires further investigation, the latter

2 explanation seems less probable since there was no concomitant decrease in the other areas of

3 coping (e.g., perception of the situation), which one might expect if the participants felt

4 overwhelmed by the forthcoming transition; rather there was an increase. Thus, it seems that

5 the combination of informational support via role models and the teaching and practicing of

6 transition-related skills was effective in bringing about an increase in perceived coping skills

7 in these participants, but that care must be taken regarding the nature of delivery of

8 information.

It should also be noted by practitioners and coaches that those approaching transition are not necessarily minded, or individually able, to prepare for the transition through seeking understanding and knowledge. Indeed, the logistics of many elite sports, including tennis, means that contact with senior athletes is difficult. Due to senior tour in tennis spanning 11 months of the year, and with tournaments across the globe, role models may often be remote figures and prove to be inaccessible. Perhaps even more tellingly, one of the participants intimated that they may not have looked for such information even if it was readily available, because there was a misconception that the participants knew everything that there was to know. This can be likened to a phenomenon known as the 'Illusion of Explanatory Depth', in which people believe that they understand the world in detail, but in reality their understanding is superficial (Rozenblit \& Keil, 2002). Such an illusion of understanding may be brought about because individuals will mistake familiarity with a situation for an understanding of how it works (Stafford, 2007). It was apparent that the junior tennis players' awareness of their own knowledge was influenced by this illusion, with the players' familiarity with the tennis world (from the media and their identity as junior tennis players at 24 a high-performance center) leading them to believe that they already possessed an in-depth knowledge of what it was like to compete on the senior tour and to make the JST. 
The provision of information and insight into a new sporting environment, in

2 combination with a sense of readiness to cope with it, was reported to boost the participants'

3 self-efficacy in the manner predicted by Bandura and colleagues. More specifically,

4 observational learning (seeing how someone else had gone through the transition), gave the

5 participants confidence that it was an achievable target, and that they could also manage the

6 process (Bandura 1965, 1997; Rosenthal \& Bandura, 1978). Finally, consistent with the

7 athletic career transition model (Stambulova, 2003) this study demonstrates that providing

8 young athletes with coping resources such as knowledge, skills, and informational support as

9 part of a transition preparation program facilitates their perception of readiness to cope with

10 transition. Whilst it is not possible from the current study to examine the effect of the

11 intervention on success at transition, these athletes should be equipped with resources to

12 enable them to feel more confident in their ability to manage the transition demands, and

13 thereby avoid a crisis transition. Furthermore, it has been suggested that the higher the

14 individual's perceived efficacy to fulfill occupational roles, the better they prepare

15 themselves for their career and the greater their staying power in challenging career pursuits

16 (Bandura, Barbarabelli, Caprara, \& Pastorelli, 2001), with clear parallels with the situation

17 under investigation here.

18 In the light of the current research findings, the provision of transition intervention

19 programs is important, not just for the transition out of sport, but also for optimizing the

20 within-career transition process up to senior level. In professional and Olympic sports,

21 preparation for life after sport has historically not been considered a good use of scarce

22 resources (Anderson \& Morris, 2000). This study builds upon existing evidence (e.g., Morris

23 et al., 2015; 2016) suggesting that time spent during junior participation to take a whole

24 person approach to young athletes' development can add considerable value (Wylleman et 
1 al., 2013). Awareness of the practical benefit is increasing and should continue to be

2 promoted by both governing bodies and individual academies.

\section{Limitations, Reflections, and Future Research}

One limitation of the current study is its lack of assessment of residual effects. It is

5 therefore not certain that the positive gains in terms of knowledge and readiness to cope with

6 the transition would translate into an adaptation of behavior, or an increased chance of

7 successful navigation of the transition to senior level. Consequently, there is a need for

8 research to examine whether the benefits suggested in this study are sustained, once an

9 athlete reaches the junior-senior transition. Some of the participants in the current study are a

10 few years away from actually making the transition. However, the timing of this kind of

11 education is important, given that many young tennis players begin playing senior

12 tournaments many years before they can no longer play junior events.

13 Secondly, whilst this is a valuable first contribution to the literature, as already

14 highlighted, further research should draw upon a more rigorous experimental design. The low

15 Cronbach's alpha coefficient for the Supports subscale of the TCQ administered pre-

16 intervention, the design limitations and the small number of participants here, mean the

17 quantitative results should be interpreted with some caution. The authors have placed

18 emphasis on the perceived value of the intervention, as determined by the participants

19 (Hrycaiko \& Martin, 1996), and whilst social validation is important in this context, there is

20 also the possibility that the results and responses were due to other variables, as opposed to

21 the administration of the intervention. Finally, the dual-role of the primary researcher and

22 program leader should be noted, given her position as the sport psychologist for the tennis

23 academy at which the intervention took place. As a result, the participants were familiar (and

24 therefore comfortable) with the presence of the first author, and there was no additional sport 
1 psychology support during the intervention. The fact that she delivered the intervention and

2 collected the data may be considered a limitation due to potential social desirability effects.

In the applied context, the implementation of an intervention program of this kind

4 presents both challenges and opportunities. More specifically, the investment of time and

5 resources required by the first author to develop the program in question was significant and

6 it would therefore be expensive to replicate. Equally, there is the potential for significant

7 beneficial impact because preparation can be enhanced beyond what is likely to be available

8 at academies.

National governing bodies should therefore be encouraged to provide the content of

this study to centers who work with athletes approaching the JST. In this context, it is noteworthy that the participating athletes particularly enjoyed the opportunity to hear directly from those they look up to in their sport and that they were motivated to listen. However, their feedback underlined that the delivery of a such program should be supported by suitably

14 qualified sport scientists who are able to help young athletes interpret the information provided and to develop the appropriate coping skills. Indeed, the authors feel that athletes would also benefit from one-to-one support during the intervention, such that coping can be supported at an individual level. Suitable participants should also be carefully selected: the athletes participating here were part of an elite training program and therefore were already immersed in their sport at a high level, with significant support available. Those with less expert support may easily feel overwhelmed. Finally, the current study highlights that sporting organizations should seek to foster better relationships between junior and senior athletes, providing clear pathways for junior athletes which enable them to model appropriate professional behaviors, to become gradually exposed to the demands of senior sport and to learn from observing and interacting with senior peers.

\section{Conclusion}


Despite the aforementioned weaknesses and the need for further research to move

2 beyond this preliminary investigation, the current study remains the first (to the authors'

3 knowledge) specifically to develop, implement and evaluate a theory driven career transition

4 program designed to prepare athletes for the JST. Most importantly, this work adds to the

5 body of literature demonstrating the importance of informational support from role models

6 during preparation for transition. Programs driven by existing theory which aim to promote

7 readiness to cope with the JST deserve further research attention and testing. The current

8 study suggests that outcomes are positive for athletes, in terms of developing the knowledge

9 and coping strategies necessary for transition, and those in support of athletes can draw upon

10 this work to support athletes at this critical point in their careers.

\section{Declaration of interest}

12 As highlighted in the text, the first author was employed as a consultant sport psychologist

13 for the tennis academy at which the intervention took place. 


\section{References}

Anderson, D., \& Morris, T. (2000). Athlete lifestyle programs. In D. Lavallee \& P. Wylleman (Eds.), Career Transitions in Sport: International Perspectives (pp. 59-80). Morgantown, WV: Fitness Information Technology.

Bandura, A. (1965). Vicarious processes: A case of no-trial learning. In L. Berkowitz (Ed.), Advances in Experimental Social Psychology (Vol. 2., pp. 1-55). New York: Academic Press.

Bandura, A. (1989). Social cognitive theory. In R. Vasta (Ed.), Annals of Child Development, Vol. 6. Six Theories of Child Development (pp. 1-60). Greenwich, CT: JAI Press.

Bandura, A. (1997). Self-efficacy: The Exercise of Control. New York: Freeman.

Bandura, A., Barbarabelli, C., Caprara, G.V., \& Pastorelli, C. (2001). Self-efficacy beliefs as shapers of children's aspirations and career trajectories. Child Development, 72, 187206.

Bane, M., Elliott, B. \& Reid, M. (2016). Is there a relationship between junior and senior tennis success? ITF Coaching and Sport Science Review, 68(24): 15 - 17.

British Psychological Society (2014). Code of Human Research Ethics. Leicester, U.K.: British Psychological Society.

Brewer, B.W. (1993). Self-identity and specific vulnerability to depressed mood. Journal of Personality, 61, 343-364.

Brewer, B. W., \& Cornelius, A. E. (2001). Norms and factorial invariance of the Athletic Identity Measurement Scale. Academic Athletic Journal, 15, 103-113.

Brewer, B. W., Van Raalte, J. L., \& Linder, E. D. (1993). Athletic identity: Hercules' muscles or Achilles heel? International Journal of Sport Psychology, 24, 237-254.

Brewer, B. W., Van Raalte, J. L., \& Petitpas, A. L. (2000). Self-identity in sport career transitions. In D. Lavallee and P. Wylleman (Eds.), Career Transitions in Sport: 
International Perspectives (pp.29-43). Morgantown, WV: Fitness Information Technology.

Bruner, M. W., Munroe-Chandler, K. J., \& Spink, K. S. (2008). Entry into elite sport: A preliminary investigation into the transition experiences of rookie athletes. Journal of Applied Sport Psychology, 20, 236-252.

6 Cassidy, C., \& Trew, K. (2004). Identity change in Northern Ireland: A longitudinal study of students' transition to university. Journal of Social Issues, 60, 523-540.

Danish, S.J., Petitpas, A.J., \& Hale, B.D. (1995). Psychological interventions with athletes: A life development model. In S. Murphy (Ed.), Clinical Sport Psychology (pp. 19-38). Champaign, IL: Human Kinetics.

Franck, A. Stambulova, N.B, \& Weibull, F. (2016). Profiles of personal characteristics and relevant pathways in the junior-to-senior transition: A longitudinal study of Swedish athletes. International Journal of Sport Psychology, 47, 483-507.

Grove, J. R., Lavallee, D., Gordon, S., \& Harvey, J. H. (1998). Account-making: a model for understanding and resolving distressful reactions to retirement from sport. The Sport Psychologist, 12, 52-67.

Higgins, E.T. (1987). Self-discrepancy: A theory relating self and affect. Psychological Review, 94, 319-340.

Houle, J. L. W., Brewer, B. W., \& Kluck, A. S. (2010). Developmental trends in athletic identity: A two-part retrospective study. Journal of Sport Behavior, 33(2), 146-159.

Hrycaiko, D., \& Martin, G. L. (1996). Applied research studies with single-subject designs: Why so few. Journal of Applied Sport Psychology, 8, 183-199.

Lavallee, D. (2005). The effect of a life development intervention on sports career transition adjustment. The Sport Psychologist, 19, 193-202. 
1 Mageau, G.A., \& Vallerand, R.J. (2003). The coach-athlete relationship: A motivational model. Journal of Sports Sciences, 21, 883-904.

Matthews, A., Farrow, D., Macmahon, C., \& Weissensteiner, J. (2012). Talent and expertise: Examining the barriers and facilitators of the junior to senior transition experience in Australian tennis-An in-depth analysis of the journey towards a professional tennis career. Journal of Sport \& Exercise Psychology, 34, S48-S49.

Morris, R., Tod, D., \& Oliver, E. (2015). An analysis of organizational structure and transition outcomes in the youth-to-senior professional soccer transition. Journal of Applied Sport Psychology, 27, 216-234.

Morris, R., Tod, D. \& Oliver, E. (2016). An Investigation Into Stakeholders' Perceptions of the Youth-to-Senior Transition in Professional Soccer in the United Kingdom. Journal of Applied Sport Psychology, 28 (4), 375-391.

Mussweiler, T., Gabriel, S., \& Bodenhausen, G. V. (2000). Shifting social identities as a strategy for deflecting threatening social comparisons. Journal of Personality and Social Psychology, 79, 398-409.

Pearson, R.E., \& Petitpas, A.J. (1990). Transitions of athletes: Developmental and preventive perspectives. Journal of Counseling and Development, 69, 7-10.Poczwardowski, A., Diehl, B., O’Neil, A., Cote, T., \& Haberl, P. (2013). Successful transitions to the Olympic Training Center, Colorado Springs: A mixed-method exploration with six resident athletes. Journal of Applied Sport Psychology, 26, 33-51.

Pummell, E. \& Lavallee, D.E. (2009). Development of a Model of Junior-to-Senior Transition. Symposium on Career Development and Transition Research: An International Perspective. In: Proceedings of the 12th World Congress of Sport Psychology [CD]. International Society of Sport Psychology. 
1 Pummell, B., Harwood, C., \& Lavallee, D. (2008). Jumping to the next level: Examining the within-career transition of the adolescent event rider. Psychology of Sport and Exercise, 9, 427-447.

Rosenthal, \& Bandura, A. (1978). Psychological modelling: Theory and practice. In S.L. Garfield \& A.E. Bergin (Eds.), Handbook of Psychotherapy and Behavior Change: An Empirical Analysis (2 ${ }^{\text {nd }}$ ed., pp. 621-658). New York: Wiley.

Rosier, N., Wylleman, P., De Bosscher, V., \& Van Hoecke, J. (2015). A quantitative study of the changes and difficulties during the transition from junior to senior elite athlete. In M. Tummino, M. Bollati, \& M. Widmann (Eds.), The 14th European Congress of Psychology: Linking technology and psychology: feeding the mind, energy for life (pp. 914-914). Milan: Innexta S.r.1..

Rozenblit, L., \& Keil, F. C. (2002). The misunderstood limits of folk science: An illusion of explanatory depth. Cognitive Science, 26, 521-562

Schlossberg, N. (1981). A model for analyzing human adaptation to transition. The Counseling Psychologist, 9(2), 2-18.

Schlossberg, N. (1993). Transition Coping Questionnaire. Minneapolis, MN: Personnel Decisions.

Schlossberg, N., Waters, E.B., \& Goodman, J. (1995). Counseling Adults in Transition: Linking Practice with Theory. New York: Springer.

Stafford, T. (2007). Isn't it all obvious? The Psychologist, 2, 94-95.

Stambulova, N.B. (2000). Athlete's crises: A developmental perspective. International Journal of Sport Psychology, 31(4), 584-601.

Stambulova, N. B. (2003). Symptoms of a crisis-transition: A grounded theory study. In N. Hassmen (Ed.), Svensk Idrottspykologisk Fo“rening (pp. 97-109). Örebro, Sweden: Örebro University Press. 
1 Stambulova, N. (2009). Talent development in sport: A career transitions perspective. In E. Tsung-Min Hung, R. Lidor, \& D. Hackfort (Eds.), Psychology of sport excellence (pp. 63-74). Morgantown, WV: Fitness Information Technology.

Stambulova, N. (2017). Crisis-transitions in athletes: current emphases on cognitive and contextual factors. Current Opinion in Psychology, 16, 62-66.

Stambulova, N., Alfermann, D., Statler, T., \& Côté, J. (2009). ISSP position stand: career development and transition of athletes. International Journal of Sport and Exercise Psychology, 7, 395-412.

Stambulova, N.B., Franck, A. \& Weibull, F. (2012). Assessment of the transition from juniorto-senior sports in Swedish athletes. International Journal of Sport and Exercise Psychology, 10, 1-17.

Stambulova, N.B., Pehrson, S. \& Olsson, K. (2017). Phases in the junior-to-senior transition of Swedish ice hockey players: From a conceptual framework to an empirical model. International Journal of Sports Science \& Coaching, 12 (2), 231-244.

Vanden Auweele, Y., De Martelaer, K., Rzewnicki, R., De Knop, P., \& Wylleman, P. (2004). Parents and coaches: A help or harm? Affective outcomes for children in sport. In: Vanden Auweele Y (ed.) Ethics in youth sport. Leuven, Belgium: Lannoocampus, 2004, pp.179-194.

Wylleman, P., Reints, A., \& De Knop, P. (2013). A developmental and holistic perspective on the athletic career. In L. Wei (Ed.), Abstracts of the ISSP 13th World Congress of Sport Psychology. (p. 2). Beijing: ISSP - Beijing Sport University.

Wylleman, P., Rosier, N., De Brandt, K., \& De Knop, P. (2016). Coaching athletes through career transitions. In R.C. Thelwell, C., Harwood, and I.A. Greenlees (Eds.), The psychology of sports coaching: Research and Practice (pp.7-20). Oxford, U.K.: Routledge. 
1 Table 1.

2 Content of the within-career transition intervention program

\begin{tabular}{|c|c|c|}
\hline $\begin{array}{c}\text { Week } \\
\text { number }\end{array}$ & Topic & Content of session \\
\hline 1 & $\begin{array}{l}\text { Baseline } \\
\text { assessment } \\
\text { and } \\
\text { introduction } \\
\text { to the junior- } \\
\text { to-senior } \\
\text { transition }\end{array}$ & $\begin{array}{l}\text { Exploring the path of current senior players through the } \\
\text { rankings from junior to senior. } \\
\text { - Video: Role models discuss their transition from junior to } \\
\text { senior. } \\
\text { - How the senior tour works, what tournaments there are, } \\
\text { ranking points. } \\
\text { Identify questions for senior players/ former players (now } \\
\text { coaches) about the transition. }\end{array}$ \\
\hline 2 & $\begin{array}{l}\text { Performance } \\
\text { and lifestyle } \\
\text { adjustments }\end{array}$ & $\begin{array}{l}\text { Videos: Lifestyle of senior player, travelling, diet, financial } \\
\text { considerations, performance differences between junior and } \\
\text { senior level. } \\
\text { - Participants complete performance profile of lifestyle and } \\
\text { performance adjustments. } \\
\text { - Goal-setting. }\end{array}$ \\
\hline 3 & Mental skills & $\begin{array}{l}\text { - Videos: Mental skills at senior level. } \\
\text { - Discussion: Progress of current senior players' careers, } \\
\text { mental skills, and adjustment to the demands of senior } \\
\text { tennis. }\end{array}$ \\
\hline 4 & $\begin{array}{l}\text { Professional } \\
\text { behaviors }\end{array}$ & $\begin{array}{l}\text { - Videos: Professional behaviors, match preparation, match } \\
\text { reflection. } \\
\text { - Discussion and planning of match preparation. }\end{array}$ \\
\hline 5 & $\begin{array}{l}\text { Independence/ } \\
\text { responsibility }\end{array}$ & $\begin{array}{l}\text { - Videos: Independence on tour, responsibility. } \\
\text { Discussion: Identifying opportunities to show greater } \\
\text { independence. }\end{array}$ \\
\hline 6 & $\begin{array}{l}\text { Scheduling of } \\
\text { tournaments }\end{array}$ & $\begin{array}{l}\text { Videos: Scheduling tournaments and scheduling tips, } \\
\text { tournament planning and training blocks. }\end{array}$ \\
\hline 7 & $\begin{array}{l}\text { Transition } \\
\text { preparation }\end{array}$ & $\begin{array}{l}\text { - Videos: Transition preparation experiences and tips. } \\
\text { - Discussion: What can I do to prepare now? } \\
\text { - Goal setting. }\end{array}$ \\
\hline 8 & Setbacks & $\begin{array}{l}\text { - Videos: Setbacks on tour, coping strategies. } \\
\text { - Discussion: Coping with setbacks, support structures. }\end{array}$ \\
\hline 9 & $\begin{array}{l}\text { Commitment } \\
\text { and lifestyle } \\
\text { balancing }\end{array}$ & $\begin{array}{l}\text { - Videos: Lifestyle, sacrifices. } \\
\text { - Discuss commitment, balancing academic, athletic and } \\
\text { social development. }\end{array}$ \\
\hline 10 & $\begin{array}{l}\text { Stages of the } \\
\text { transition }\end{array}$ & $\begin{array}{l}\text { - Videos: Experience of the phases of the JST, life of a player } \\
\text { ranked } 300 . \\
\text { - Discuss transition progress. } \\
\text { - Goal setting. }\end{array}$ \\
\hline
\end{tabular}

Note. Each session concluded with participant reflections on the material covered. Week numbers two to 10 began with a review and discussion of participant reflections, participants' diary reflections and any discussions or interactions they had had with current and former senior players since the previous session. 
Table 2

2

Mean athletic identity, knowledge for the transition, and readiness to cope with transition across the three assessment points $(n=7)$.

\begin{tabular}{lllll}
\hline & Time 1 $(S D)$ & Time 2 $(S D)$ & \multicolumn{1}{l}{ Time 3 (SD) } \\
\hline Athletic identity & $38.57(4.24)$ & $38.43(4.28)$ & $38.43(5.13)$ & 6 \\
\hline Knowledge & $72.96(17.15)$ & $113.84(24.06)$ & $122.34(20.47)$ \\
\hline Readiness: Total & $106.57(17.14)$ & $108.43(20.38)$ & $120(21.94)$ & \\
\hline Readiness: Situation & $22.71(3.15)$ & $24.14(4.98)$ & $27.71(5.15)$ & 8 \\
\hline Readiness: Self & $29.0(7.66)$ & $29.57(6.70)$ & $32.71(6.82)$ & 9 \\
\hline Readiness: Supports & $22.57(3.69)$ & $20.86(3.08)$ & $23.0(3.32)$ & 10 \\
\hline Readiness: Strategies & $32.29(6.16)$ & $33.86(7.80)$ & $36.58(8.16)$ &
\end{tabular}

12 